Elsevier required licence: (C) $<2020>$. This manuscript version is made available under the CC-BY-NCND 4.0 license http://creativecommons.org/licenses/by-nc-nd/4.0/

The definitive publisher version is available online at

[https://www.sciencedirect.com/science/article/abs/pii/S0960852419318838?via\%3Dihub] 


\section{Contribution of antibiotics to the fate of antibiotic resistance genes in anaerobic treatment processes of swine wastewater: a review}

Dongle Chenga ${ }^{\mathrm{a}}$, Huu Hao Ngo ${ }^{\mathrm{a}, \mathrm{b}, \mathrm{c}^{*}}$, Wenshan Guo ${ }^{\mathrm{a}, \mathrm{b}}$, Soon Wang Chang ${ }^{\mathrm{c}}$, Dinh Duc Nguyen ${ }^{\mathrm{c}, \mathrm{d}}$, Yiwen Liu $^{\mathrm{a}}$, Xinbo Zhang ${ }^{\mathrm{b}}$, Xue Shan ${ }^{\mathrm{b}}$, Yi Liu ${ }^{\mathrm{f}}$

${ }^{a}$ Centre for Technology in Water and Wastewater, School of Civil and Environmental Engineering, University of Technology Sydney, Sydney, NWS 2007, Australia

${ }^{b}$ Joint Research Centre for Protective Infrastructure Technology and Environmental Green Bioprocess, Department of Environmental and Municipal Engineering, Tianjin Chengjian University, Tianjin 300384, China

${ }^{c}$ Department of Environmental Energy Engineering, Kyonggi University, 442-760, Republic of Korea ${ }^{d}$ Institution of Research and Development, Duy Tan University, Da Nang, Vietnam

${ }^{e}$ NTT Institute of Hi-Technology, Nguyen Tat Thanh University, Ho Chi Minh City, Vietnam ${ }^{f}$ Department of Environmental Science and Engineering, Fudan University, 2205 Songhu Road, Shanghai 200438, PR China

* Corresponding authors: E-mail address: ngohuuhao121@gmail.com

\section{Abstract}

Antibiotic resistance genes (ARGs) in water environment have become a global health concern. Swine wastewater is widely considered to be one of the major contributors for promoting the proliferation of ARGs in water environments. This paper comprehensively reviews and discusses the occurrence and removal of ARGs in anaerobic treatment of swine wastewater, and contributions of antibiotics to the fate of ARGs. The results reveal that ARGs' removal is unstable during anaerobic processes, which negatively associated with the presence of antibiotics. The abundance of bacteria carrying ARGs increases with the addition of antibiotics and results in the spread of ARGs. The positive relationship was found between antibiotics and the abundance and transfer of ARGs in this review. However, it is necessary to understand the correlation among antibiotics, ARGs and microbial communities, and obtain more knowledge about controlling the dissemination of ARGs in the environment. Keywords: Antibiotics, antibiotic resistance genes, anaerobic treatment processes, swine wastewater 


\section{Introduction}

Antibiotics are the most effective agents used in pig farms to prevent and treat disease, as well as improve the growth of pigs (Li, 2017; Sarmah et al., 2006). Landers et al. (2012) reported that approximately $88 \%$ of growing pigs in the United States receive antibiotics in their feed for disease prevention and growth promotion purposes. In Japan, 175 tons of antibiotics were used as growth promotion to animals in 2001 (Li, 2017). Nearly half of the antibiotics consumed (162,000 tons in 2013) were used in animal husbandry (Zhang et al., 2015b). However, most antibiotics are poorly absorbed by pigs and hence are excreted through faeces and urine of pigs in unchanged forms or as metabolites (Álvarez et al., 2016; Cheng et al., 2018b). Therefore, swine wastewater has been reported as an important reservoir of antibiotics due to the frequent use of antibiotics for controlling disease and in the growth of pigs (Apley et al., 2012; Chen et al., 2018; Sui et al., 2017).

The high frequency and detection of ARGs in swine wastewater reflected the positive relationship between ARGs and their corresponding antibiotic concentrations (Wang et al., 2016a). He et al. (2016) states that ARGs in swine wastewater samples were at least 31 times higher than those in well water and fishpond water. Ben et al. (2017) investigated the ARGs' encoding resistance to tetracycline antibiotics in nine swine feedlots located in Shandong Province of China. Results indicate that targeted ARGs were widely distributed in swine wastes, with the mean relative abundance (copies per 16S rRNA gene) ranging from $3.3 \times$ $10^{-5}($ tet $\mathrm{C})$ to $5.2 \times 10^{-1}($ tet $\mathrm{O})$ in swine manure and from $7.3 \times 10^{-3}($ tet $\mathrm{C})$ to $1.7 \times 10^{-1}$ (tet $\mathrm{O})$ in swine wastewater. Moreover, high levels of ARGs have been detected in soil and water environments adjacent to swine farms (Cheng et al., 2016; He et al., 2016; Hsu et al., 2014; Wu et al., 2010). Wu et al. (2010) found that the absolute tetracycline resistance gene copies (sum of tet $\mathrm{M}$, tet $\mathrm{O}$, tet $\mathrm{Q}$, tet $\mathrm{W}$ genes) in soils, which received pig wastes strongly correlated with the concentrations of tetracycline residues. Li et al. (2018b) explained that 
antibiotics together with ARGs (i.e., qnrA, sul1, sul2, tet $\mathrm{G}$, tet $\mathrm{M}$, and tet $\mathrm{O}$ ) discharged from swine feedlots through wastewater could disseminate into surrounding groundwater environments. The total relative abundance of ARGs also increased in the river water after receiving swine wastewater discharge (Jia et al., 2017). The presence of ARGs in the environment could pose a serious risk to aquatic and terrestrial life because of their spread in the environment through bacteria, and/or mobile genetic elements (Li et al., 2018a; Xie et al., 2016). As emerging environmental contaminants, ARGs have become one of the world's most serious clinical and public health issues as indicated by the first global report of the World Health Organization (WHO) on antimicrobial resistance (WHO, 2014). According to the latest report, a new superbug, Staphylococcus epidermidis, which is resistant to all known antibiotics has been discovered by Australian scientists (Lee et al., 2018). The increased resistance, including multi-drug resistance, supports urgent research that the factors and hot spots involved in its diffusion and development should be better understood (Lupo et al., 2012).

Anaerobic treatment technology is one of the main methods for treating swine wastewater with high organic pollutants, since biogas generated could be used as bioenergy for households and anaerobic digestion residue usually applied as organic fertilizers to facilitate the growth of crops (Jechalke et al., 2014; Skouteris et al., 2012; Sui et al., 2016). However, anaerobic treatment processes not only have limited capability to completely remove antibiotics and ARGs received from swine wastewater they can, in turn, create favorable conditions for ARGs development and transfer (Miller et al., 2016; Pu et al., 2018; Zhang, 2016). Hence, products from the anaerobic treatment process have been regarded as the source of antibiotics, and ARGs brought into the environment (Sui et al., 2016). 
To date, previous studies have focused on factors contributing to the proliferation and spread of ARGs in anaerobic treatment processes, such as antibiotics, heavy metals, operational conditions, and microbial communities (Ma et al., 2011; Sun et al., 2016; Yin et al., 2017). Exposure to antibiotics has been considered as the most important factor influencing the emergence and spread of ARGs (Allen et al., 2010; Gao et al., 2012b; Levy, 2002). Therefore, it is necessary to focus on the contribution of antibiotics on ARGs in the anaerobic treatment of swine wastewater due to the significantly high concentrations of antibiotics in swine wastewater (Cheng et al., 2018b). Horizontal Gene Transfer (HGT) has been confirmed as a major contributor to the spread of ARGs, which have specific structures and ability to capture genes by a site-specific recombination system (Lopatkin et al., 2016a). Furthermore, ARGs are carried by microbes in anaerobic treatment processes, so changes in the structure of the bacterial community is the dominant mechanism responsible for the variation of ARGs and during anaerobic processes (Tong et al., 2016; Zhang et al., 2016). It should be noted that antibiotics in swine wastewater show significant effects on the microbial community in anaerobic processes (Akyol et al., 2016; Cheng et al., 2018a). It can be considered that the impacts of antibiotics on HGT and the microbial communities can also demonstrate diverse influences on ARGs. Therefore, the goal of this paper is to figure out the influence of antibiotics on ARCs through their impacts on HGT and the microbial communities related to ARGs. Although studies have focused on the removal of antibiotics and ARGs during the anaerobic process, the occurrence and spread of ARGs continues to be a problem (He et al., 2016; Sui et al., 2016; Sun et al., 2016). Understanding the contribution of antibiotics to the fate of ARGs during anaerobic treatment of swine wastewater is critical for reducing the spread of ARGs through the wastewater treatment process. Hence, this review is focused on the occurrence and removal of ARGs in swine 
wastewater treatment by anaerobic processes, and the contributions of such antibiotics to the abundance and transfer of ARGs.

\section{Occurrence and removal of ARGs in the anaerobic treatment of swine wastewater}

Antibiotics in the class of tetracyclines, sulfonamides, and macrolides are known as the frequently used antibiotics in swine farms (Cheng et al., 2018b; Hsu et al., 2014). High concentrations of such antibiotics have been found in swine wastewater. As reviewed by Cheng et al. (2018b), antibiotics, such as sulfamethoxazole (SMX), sulfadiazine (SDZ), sulfamonomethoxine (SMN), tetracycline (TC), oxytetracycline (OTC), chlortetracycline (CTC) and tylosin, were detected at alarmingly high levels in swine wastewater with the average concentration of $316.5,98.9,45.4,130.08,16.25,12.16$ and $72 \mu \mathrm{g} / \mathrm{L}$, respectively. In this case, ARGs, including tetracycline resistance genes, sulfonamide resistance genes, and macrolide resistance genes have been frequently detected in swine wastewater (Ben et al., 2017; Yuan et al., 2018). The class 1 integron-integrase gene (Intl1) is part of class 1 integrons that could capture ARGs as part of gene cassettes. The review paper by Gillings et al. (2015) suggested that Intl1 could be proposed as a good proxy for monitoring ARGs in the environment. Thus, Intl1 was linked to the dissemination of various ARGs (Aydin et al., 2015b; Tian et al., 2016; Zarei-Baygi et al., 2019). As reported, Intl 1 is also prevalent in swine wastewater with a proportion of up to $30 \%$ (Yuan et al., 2018).

All these ARGs were detected and highly abundant in swine wastewater. Their abundance in raw swine wastewater $\left(10^{11}-10^{14}\right.$ copies/L) is much higher than that in drinking water sources $\left(10^{4}-10^{9}\right.$ copies/L) (Su et al., 2018; Sui et al., 2016). Based on the various amounts of antibiotics used and the management of pig farms, the mean relative abundance of the selected ARGs in swine wastewater from pig farms is shown in Fig. 1 (Ben et al., 2017; Cheng et al., 2013; Joy et al., 2014; Sui et al., 2016; Wang et al., 2016a). As can be seen from Fig. 1, the mean relative abundance of the selected ARGs in swine wastewater 
ranges between $10^{-3}$ and $10^{-1}$ copies/16S rRNA, which is higher than the abundance in global lakes $\left(10^{-5}\right.$ to $\left.10^{-2}\right)$ (Yang et al., 2018). In particular, tetracycline resistance genes tetC and tet $\mathrm{O}$ were the most detected ARGs in swine wastewater with the mean relative abundance of $6.39 \times 10^{-2}$ and $1.13 \times 10^{-1}$ copies/16S rRNA, respectively (Cheng et al., 2016; Sui et al., 2016; Tao et al., 2014). Except to $t e t C$, the abundance of the ribosomal protection protein genes $($ tet $\mathrm{M}$, tet $\mathrm{O}$, tet $\mathrm{Q}$, tet $\mathrm{W})$ were higher than the efflux protein genes $(\operatorname{tet} \mathrm{A}, \operatorname{tet} \mathrm{B}, \operatorname{tet} \mathrm{G})$ in $\mathrm{swine}$ wastewater. Two plasmid-borne genes, sul1 and sul2, were also highly detected in swine wastewater, with means of $5.48 \times 10^{-2}$ and $3.23 \times 10^{-2}$ copies/16S rRNA, respectively (Cheng et al., 2016; McKinney et al., 2010; Sui et al., 2016; Tao et al., 2014). The sul1 and sul2 are associated with sulfonamide resistance in gram-negative bacteria, which produce dihydropteroate synthetase and induce resistance against sulphonamides (Arabi et al., 2014). The macrolide resistance genes, such as erm $\mathrm{B}$, erm $\mathrm{F}$, and $m e f \mathrm{~A}$, were also detected in swine wastewater with high abundance (Sui et al., 2016). Meanwhile, the mean relative abundance of intl1was $8.76 \times 10^{-3}$ copies/16S rRNA in swine wastewater (Sui et al., 2016).

\section{Figure 1}

Considering high residuals of antibiotics and ARGs in swine wastewater, recent studies about the treatment of swine wastewater by anaerobic treatment processes not only considered the removal of common contaminants and biogas production, but also their efficiencies for removing antibiotics and ARGs (Ma et al., 2018; Sui et al., 2014; Sui et al., 2016). The ARGs removal in anaerobic processes needs more attention due to the usual land application of products from the anaerobic process. As reports, the shift of ARGs in the anaerobic process was related to their resistance mechanisms and different operating conditions of anaerobic processes (Sui et al., 2016; Sui et al., 2017; Wang et al., 2017b). 
Accordingly, the intrinsic resistance mechanism of the most detectable ARGs in swine wastewater, the main hosts of these ARGs in anaerobic processes, and their shift are summarized in Table 1 (Aydin et al., 2015b; Sui et al., 2016).

\section{Table 1}

As shown in Table 1, tet $\mathrm{X}$ encoding tetracycline inactivation enzyme did consistently decrease in the anaerobic treatment of swine wastewater (Chen et al., 2015a; Cheng et al., 2013). The shift of macrolide antibiotic resistance genes (ermB and ermF), mainly documented as 23S rRNA methyltransferase genes, showed a similar trend with tetX after the treatment of anaerobic process (Yang et al., 2014). Whereas, the removal of the ribosomal protection protein genes (tet $\mathrm{W}$ and tet $\mathrm{O}$ ) was variable in different operating conditions (Wang et al., 2017b; Wu et al., 2016). Temperature was essential for ARGs removal by anaerobic treatment, the removal rates of ARGs and intl1 increased with increasing the temperature. For instance, Wang et al. (2017b) stated that predominant $\mathrm{ARGs}($ tet $\mathrm{O}$, tet $\mathrm{W}$, and tet $\mathrm{X})$ almost reduced by one order of magnitude through mesophilic anaerobic digestion $\left(37^{\circ} \mathrm{C}\right)$. The removal rates of genes (tet $\mathrm{O}$, tet $\mathrm{X}$, tet $\mathrm{W}$ and $\operatorname{int} \mathrm{I} 1)$ could be enhanced when the temperature increased from 37 to $55^{\circ} \mathrm{C}$, but quantities of some $\mathrm{ARGs}($ tet $\mathrm{A}$, tet $\mathrm{O}$, and tet $\mathrm{X})$ increased in anaerobic effluent under the temperature of $22{ }^{\circ} \mathrm{C}$ (Diehl \& LaPara, 2010). Similar results have been concluded by Wu et al. (2016), who indicated that ARGs could be much more decreased in thermophilic digestion than that in mesophilic one.

However, the relative abundances of tetracycline resistance genes $(\operatorname{tet} \mathrm{A}, \operatorname{tet} \mathrm{G}, \operatorname{tet} \mathrm{C}$ and tet $\mathrm{M}$ ), as well as the sulfonamide resistacne genes (sul1 and sul2) increased after anaerobic treatment of swine wastewater (Cheng et al., 2016; Sui et al., 2016; Tao et al., 2014). Ju et al. (2018) also observed the increase of the relative abundance of ARGs and 
intI1 in the effluent of WWTPs. This might be due to proliferation of their host bacteria during the wastewater treatment process or horizontal transfer of the ARGs to other species (Hultman et al., 2018; Koike et al., 2007). For example, Hultman et al, (2018) demonstrated that the effluent of the wastewater treatment plants contained resistance genes in bacteria not carrying these genes in the influent. Anaerobic treatment processes with a high density of bacteria have been shown to be hotspots for ARGs transfer among different microorganisms through HGT (Lopatkin et al., 2016b; Miller et al., 2016; Sørensen et al., 2005). HGT is the process of genetic movement among species, which is another major mechanism responsible for the spread of antibiotic resistance (Lopatkin et al., 2016b). As reported, tet $\mathrm{A}$, tetC and tet $\mathrm{G}$ genes can easily spread among bacteria species. This is mainly because they are carried by main mobilizable vectors, self-transmissible transposon and smaller plasmids (Jiang et al., 2013). sul1 is often associated with Intl1, it was located in the $3^{\prime}$-conserved segment $\left(3^{\prime}-\mathrm{CS}\right)$ of class 1 integrons, while sul2 gene was usually related to small non-conjugative plasmids or large transmissible multi-resistant plasmids, which could facilitate their dissemination (Ma et al., 2018). Class 1 integrons were often used to represent the HGT as it can regulate the expression of exogenous genes. Although they cannot mobilize and transfer themselves between microbes, they are often associated with genetic elements which can, such as conjugative plasmids, transposons and insertion sequences (Berglund, 2015).

Rich nutrients in swine wastewater and relatively permissive conditions for the anaerobic bacteria also can explain the inability of the anaerobic process to substantially reduce such ARGs, because the spread of ARGs could be increased by the synergistic effect of the antibiotics and nutrients in wastewater. (Chen et al., 2010; Subirats et al., 
2018). For instance, the study by Subirats et al. (2018) found that the abundance of sul1 and intI1 genes increased when bacterial communities exposed to both emerging contaminants and a high nutrient concentration $(1,25$ and $1 \mathrm{mg} / \mathrm{L}$ of phosphate, nitrate and ammonium, respectively). In addition, antibiotics in swine wastewater demonstrated statistically significant correlations with the ARGs, in which their fate in the anaerobic treatment process was linked to the level of residual antibiotics (Cheng et al., 2016). Thus, it is difficult to give a general conclusion about the removal vs. enrichment of ARGs in anaerobic treatment processes. Exploring the impact factors on the fate and transfer of ARGs in anaerobic processes is significant in future research.

\section{Contribution of antibiotics to the fate of ARGs in anaerobic processes}

High concentrations of antibiotics in swine wastewater have great effects on the fate of ARGs in the anaerobic treatment processes, although some studies have reported that besides antibiotics, other influential factors also affect the fate of ARGs (He et al., 2017; Li et al., 2010; Wang et al., 2016a). In most cases, antibiotics in swine wastewater were positively correlated with the prevalence of ARGs in the treatment process (Huang et al., 2017; Jia et al., 2017; Zhang et al., 2015a). For ARGs, these antibiotics pose strong selective pressures which facilitate their horizontal transfer among bacterial cells by plasmids or integrons during anaerobic treatment processes (Ghosh \& LaPara, 2007; Looft et al., 2012). Previous literature indicated that antibiotics even in concentrations below the minimal inhibitory concentration can increase the abundance of ARGs (Aydin et al., 2015b; Gullberg et al., 2011). The appearance of antibiotics in anaerobic reactors could show a negative effect on the removal efficiencies of ARGs (Wang et al., 2017b). Furthermore, the microbial community carrying ARGs could be influenced by 
antibiotics, which would result in the change of ARGs in anaerobic processes (Luo et al., 2017; Tong et al., 2016; Wang et al., 2014a; Zhang et al., 2013a).

\subsection{Contribution of antibiotics to the abundance of ARGs}

\subsubsection{Contribution of sulfonamides to their corresponding ARGs}

The presence of antibiotics in the anaerobic treatment process exerts direct pressure in the accumulation of ARGs. Some reports indicated that the concentration of tetracycline and sulfonamide antibiotics correlate with their corresponding ARGs

(Zarei-Baygi et al., 2019). That is, the abundance of ARGs increased with the increasing dose of antibiotics (Aydin et al., 2016; Cheng et al., 2018a; Zarei-Baygi et al., 2019). For instance, Jiang et al. (2013) found more sulfonamide resistance genes and tetracycline resistance genes in the water samples containing higher concentrations of total sulfonamide and tetracycline antibiotics. A significant increase of total ARG abundance, sul1 and ermF in particular was observed by the addition of SMX and the increment of its concentration from 10 to $250 \mu \mathrm{g} / \mathrm{L}$ (Zarei-Baygi et al., 2019). Aydin et al. (2015b) predicted that ARGs develop rapidly as they become stable in bacterial populations in reactors of higher or lethal antibiotic concentrations in comparison to reactors with lower or non-lethal antibiotic concentrations. In particular, along with the swine wastewater treatment process, a strong positive correlation between the total relative abundance of sulfonamide resistance genes and the total sulfonamides concentration was observed (Ma et al., 2018; Wang et al., 2016a). In a constructed wetlands system for treating swine wastewater, the author also indicated that the increase of the relative abundance of tet $\mathrm{W}$, tet $\mathrm{O}$, tet $\mathrm{M}$, sull and sul2 genes was mainly caused by SMZ and TC accumulation in the system (Cheng et al., 2018a). 
These similar results were found in the conventional wastewater treatment plant and fish pond waters, as the increased quality of sul1 genes were observed in the samples with a higher concentration of sulfonamides (Gao et al., 2012b; He et al., 2017). It is reported that the relatively high water solubility and stability of sulfonamides could promote the spread of antibiotic resistance (Chee-Sanford et al,, 2009). More explicitly, according to the transfer mechanism of sulfonamide resistance genes, the sull gene was usually accompanied by the presence of integrons as it contributes to the widespread of sul1 in the aquatic environment (Gao et al., 2012a).

\subsubsection{Contribution of tetracyclines to their corresponding ARGs}

Compared with sulfonamides, tetracyclines can be easily absorbed into the anaerobic sludge through adsorption (Cheng et al., 2018b). Thus, the abundance of tetracycline resistance genes was reported as being higher in the residual sludge rather

than those in the effluent wastewater (Aydin et al., 2016; Wu et al., 2016). Huang et al. (2015a) reported that in the anaerobic reactor with TC, almost all target tetracycline resistance genes $($ tet $\mathrm{A}$, tet $\mathrm{B}$, tet $\mathrm{C}$, tet $\mathrm{E}$, tet $\mathrm{M}$, tet $\mathrm{O}$, tet $\mathrm{S})$ proliferated in the sludge more than those in the reactor without TC. Smith et al. (2004) also concluded that tetracycline resistance genes were positively selected after exposure to high levels of TC, the total abundance of ARGs was significantly increased at high TC levels. Therefore, the adsorption of tetracyclines in biomass during the treatment process plays an important role in increasing tetracycline resistance genes in the anaerobic sludge (Aydin et al., 2016). The appearance of OTC in the anaerobic reactor also benefit the proliferation of ARGs. For example, there were more abundant tetracycline resistance genes presented in an OTC wastewater treatment system than those in sewage treatment systems (Liu et al., 2012). Interestingly, the abundance of efflux pump genes (tet $\mathrm{A}$, tet $\mathrm{B}$, and tet $\mathrm{C}$ ) in 
the reactor with OTC (2 mg/L) and TC were significantly higher than in the control reactor (He et al., 2017; Shi et al., 2017). This explains how most of the efflux pump genes could be acquired or transferred through mobile elements, which is the dominant mechanism for the dissemination of ARGs (Jiang et al., 2013; Wang et al., 2014b).

When antibiotics show different influences on various ARGs, the abundance of some ARGs could be improved while other ARGs were not affected. This explains the different responses of various ARGs to antibiotics (Wu et al., 2015). As reported earlier, although the abundance of efflux pump genes (tet $\mathrm{A}, \operatorname{tet} \mathrm{B}$, and tet $\mathrm{C})$ increased with the increase of OTC concentration, the enzymatic modification gene (tet X) did not fluctuate significantly (Shi et al., 2017). The reason might be that the resistance mechanism of efflux pump is only a self-protection mechanism of microbes, which cannot reduce antibiotic content, whereas the enzymatic modification gene is one of the main mechanisms of tetracycline degradation that can chemically modify tetracycline to inactivate it via synthetic oxidoreductase expression (Chopra \& Roberts, 2001). In the anaerobic processes, Bacteroides spp. which carry tet $\mathrm{X}$, modifies antibiotics and degrades it via the tet $\mathrm{X}$ protein (a flavin-dependent monooxygenase) (Yang et al., 2004). According to the report by Wang et al. (2016b), the abundance of tetQ and tet W genes increased when OTC concentration also increased, while tet $\mathrm{M}$ and tet $\mathrm{C}$ genes decreased due to the OTC inhibition of microbes.

\subsubsection{Co-resistance and cross-resistance of antibiotics}

Alternatively, some reports also concluded that the correlation between total ARGs and their corresponding antibiotics was not as significant as previously thought; other factors may also influence the abundance of ARGs in addition to the selection pressure of antibiotics (Ji et al., 2012; McKinney et al., 2010; Peak et al., 2007; Selvam et al., 
2012; Wang et al., 2016a). For instance, Selvam et al. (2012) found that regarding the treatment of swine manure, in most cases, the copy number of ARGs in the reactor with antibiotics was higher than the control reactor. However, in some aspects, more ARGs were detected in control reactors compared with antibiotic spiked ones. As well, in both swine treatment lagoons and the municipal wastewater treatment plant, although a positive correlation was observed between total sulfonamide resistance genes and total sulfonamides in wastewater, no significant correlation was found between total tetracycline resistance genes and total tetracyclines (Gao et al., 2012b; Zhang et al., 2013b). The reason might be that many other factors could also affect the spread of ARGs in wastewater at low concentrations of antibiotics, which would result in a weak correlation between antibiotics and their corresponding resistance genes throughout the wastewater treatment process (Gao et al., 2012b). Probably, other factors, for instance heavy metals and other types of antibiotics presenting in the wastewater, can result in co-selection and cross-selection of resistance, which may affect correlations between ARGs and their corresponding antibiotics (McKinney et al., 2010; Stepanauskas et al., 2006).

As reported by Ji et al. (2012), due to the coexistence of antibiotics and heavy metals, significant positive correlations were found between sulfonamide resistance gene and typical heavy metals $(\mathrm{Cu}, \mathrm{Zn}$ and $\mathrm{Hg})$, while the presence of ARGs was relatively independent of their respective antibiotic inducer. Li et al. (2015) also indicated that the correlation not only just occurred between ARGs and their corresponding antibiotics, but is still true for other types of antibiotics, for instance, the slufamerazine indicated a positive relationship with tetracycline resistance genes (tet $\mathrm{B}$ and tetC). In a landfill, OTC and TC showed positive correlations with tet $\mathrm{O}$ and sul1, 
while SMX was not found to be associated with the ARGs investigated (Song et al., 2016). Also, a high concentration of OTC could improve the relative abundance of $d r f A 7$, a sulfonamide resistance gene (Qian et al., 2016). All of the above may be due to the co-resistance and cross-resistance of the two classes of antibiotics.

During the anaerobic treatment process, the number of ARGs would reduce due to the effective degradation of antibiotics (Mohring et al., 2009). Aydin et al. (2015b) and Aydin et al. (2016) indicated that the concentration of tetracycline resistance genes was always higher than the erythromycin resistance genes in the reactor with tetracycline and erythromycin (ERY), even though the dosage of tetracycline was the same as that of ERY. This is mainly because the biodegradation of tetracycline could be lower than ERY in biological wastewater treatment. According to the report by Shi et al. (2017), OTC did benefit the proliferation and accumulation of ARGs in the anaerobic reactor, but the abundance of ARGs displayed a downward trend when the antibiotic selective pressure was removed. This also has been confirmed by the treatment of swine wastewater by constructed wetlands, which demonstrated that the higher influent TCs concentration selected more copy numbers of Intl1, tet $\mathrm{A}$ and tet $\mathrm{W}$ in the effluent. Thereafter, however, this selection effect was alleviated probably because of elevated antibiotics removal (Huang et al., 2015b).

Additionally, ARGs increased with an increased dosage of combined antibiotics (sulfamethoxazole-tetracycline-erythromycin (STE) and sulfamethoxazole-tetracycline (ST)) (Aydin et al., 2015a). This outcome has been confirmed by Aydin et al. (2015b), who compared the proliferation of ARGs in the reactors with individual and combined antibiotics, respectively. These findings indicated that the presence of antibiotic combinations resulted in higher rates of ARG acquisition than individual antibiotics. 
The author also stated that the effluent from the STE reactor had a higher number of ARGs than in the ST reactor due to the synergistic effects of ERY. He et al. (2017) have also concluded that the total relative abundance of ARGs in combined stresses exposure tanks (tetracycline-sulfanilamide, tetracycline-sulfanilamide-cefotaxime, tetracyclinesulfanilamide- $\mathrm{Cu}$, and tetracycline-sulfanilamide-Zn) was about 1.01-1.55 times more than the sum of their individual ones.

\subsection{Contribution of antibiotics to the transfer of antibiotic resistant genes}

One of important factors for the proliferation and transfer of ARGs is the HGT with MGEs, as they have specific structures and the ability to capture genes by a sitespecific recombination system (Hershberg, 2017). Anaerobic treatment processes with a high density of bacteria have been shown to be hotspots for ARGs transfer among different bacteria through HGT (Lopatkin et al., 2016b; Miller et al., 2016; Sørensen et al., 2005). The transfer of ARGs among bacteria mainly include three pathways: 1. Bacteria transformation; 2. Bacteria transduction; 3. Bacteria conjugation (see Fig. 2). The figure explains how the process of transformation, naked DNA and ARGharbouring mobile genetic elements (MGEs) released by the donor cell and taken up by bacteria and incorporated into the genome (Chen \& Dubnau, 2004). While in transduction, phages can act as vectors for genetic exchange, whereby ARGs are carried by phage particles from a donor bacterial cell to a recipient cell (Balcazar, 2014).

\section{Figure 2}

Previous studies reported that antibiotics could contribute to antibiotic resistance by enhancing their spread among the bacterial community under non-lethal concentrations (Beaber et al., 2004; Jutkina et al., 2018; Úbeda et al., 2005). Thus, it 
was believed that the selective pressure from antibiotics could accelerate the ARGs' transmission in the sensitive bacteria (Li et al., 2009). For example, Aydin et al. (2015b) concluded that high levels of antibiotics have shown abilities to increase and stimulate HGT, and activate MGEs among the bacterial community. The study by Jutkina et al. (2018) also concluded that SMX (1 mg/L) and gentamicin $(0.1 \mathrm{mg} / \mathrm{L})$ significantly increased the transfer frequency of antibiotic resistance. Therefore, the transfer of ARGs could be enhanced by the presence of antibiotics in anaerobic processes.

\subsubsection{Contribution of antibiotics to transfer through conjugation}

Conjugation plays an important role in the association of ARGs with MGEs, which occurs either through plasmid transfer or transmission of chromosomally integrated conjugation elements, including conjugative transposons (Aminov, 2011; Frost et al., 2005; Wozniak \& Waldor, 2010). As reported in one study, the abundance of sulfonamide resistance genes significantly correlated with the abundance of plasmids (Tao et al., 2016). In addition, most efflux protein tetracycline resistance genes, such as $t e t \mathrm{~A}, t e t \mathrm{~B}$, tet $\mathrm{C}$ and $t e t \mathrm{G}$, can easily spread among bacteria species. This is mainly because they are carried by main mobilizable vectors, these being self-transmissible transposon and smaller plasmids (Jiang et al., 2013). In addition, tet $\mathrm{W}$, tet $\mathrm{O}$, tet $\mathrm{S}$, sul2 and sul3 are commonly found on conjugative plasmids or chromosomes transferred horizontally between microbial communities (Billington et al., 2002; Wu et al., 2016). Due to the high prevalence and the broad host ranges of plasmids, as well as the ARGs carried by many plasmids, conjugation is thought to be responsible for the majority of antibiotic resistance spread (Lopatkin et al., 2016b)

Some studies supposed that antibiotics could promote HGT through conjugation. They can the increase the conjugation efficiency through activating the excision of 
transferrable genes from the host chromosome and/or by inducing the expression of conjugation machinery (Beaber et al., 2004; Stevens et al., 1993). The study by Scornec et al. (2017) indicated that some ribosome-targeting antibiotics could increase the conjugation frequency of a specific conjugative transposon more than a thousand-fold. Lopatkin et al. (2016b) showed that antibiotics determine conjugation dynamics primarily by serving as a selective driver in a broad range of conjugative systems. Tetracycline and SMX have been reported as potent inducers of conjugation by recent researches (Jutkina et al., 2018; Jutkina et al., 2016). However, the effect of antibiotics on HGT by conjugation is still controversial. For instance, antibiotics ciprofloxacin CIP and ERY have no inductive effects on conjugal transfer (Lopatkin et al., 2016a; López et al., 2007). In particular, antibiotics can promote and suppress HGT dynamics, depending on how antibiotics affect growth rates of populations undergoing conjugation (Lopatkin et al., 2016b). Lu et al. (2017) investigated the effect of antibiotics on conjugational transfer of a mobilizable gentamicin resistance plasmid, and concluded that the conjugation-promoting ability of antibiotics was controlled by the quorum sensing. The study by Lopatkin et al. (2016a) also indicated that the contribution of antibiotics to the promotion of conjugation might be over-estimated. The reason is that: firstly, the efficiency of conjugation antibiotics was not significantly increased by antibiotics, and secondly, antibiotics might reduce the frequency of conjugation by reducing the population sizes of either or both parental populations, which would negate the effect of positive selection for the transconjugant.

\subsubsection{Contribution of antibiotics to transfer through integrons}

An integron is a typical gene capture and dissemination system. Integrons are ubiquitous in chromosomes and MGEs, like plasmids and transposons (Chen et al., 
2015b; Guerin et al., 2009). They play a key role in the dissemination of ARGs by facilitating horizontal transfers of ARGs between microbes through combination with mobile gene platforms and/or incorporating ARGs into microbial chromosomes (Gillings et al., 2015; He et al., 2016). Class 1 integrons were often used to represent the HGT as it can regulate the expression of exogenous genes. Although they cannot mobilize and transfer themselves between microbes, they are often associated with genetic elements which can, such as conjugative plasmids, transposons and insertion sequences (Berglund, 2015). The most detectable antibiotics in swine wastewater and class 1 integrase genes have been considered to be key markers of HGT in the anaerobic process (Ghosh et al., 2009; Ma et al., 2011; Miller et al., 2013). Intl1 is part of class 1 integrons which could capture ARGs as part of gene cassettes, thus Intl1 was linked to the transfer of ARGs (Aydin et al., 2015b; Tian et al., 2016).

For example, for ARGs in the treatment of swine wastewater when utilizing the anaerobic process, tet $\mathrm{A}, \operatorname{tet} \mathrm{C}, \operatorname{tet} \mathrm{G}, \operatorname{tet} \mathrm{Q}, \operatorname{tet} \mathrm{X}, \operatorname{sul} 1, \operatorname{erm} \mathrm{B}$, and $d f r A 1$ were found to be positively correlated with Intl1 (Chen et al., 2015b; Cheng et al., 2013; Liu et al., 2012; Sui et al., 2017; Wu et al., 2016). Specifically, sul1 gene was located in the $3^{\prime}$ conserved segment ( $\left.3^{\prime}-\mathrm{CS}\right)$ of class 1 integrons, while sul2 gene was usually related to small non-conjugative plasmids or large transmissible multi-resistant plasmids (Ma et al., 2018). Although tetracycline resistance genes have not been found as gene cassettes in class 1 integrons, they have been associated with class 1 integrons on selftransferable plasmids in both gram-positive and gram-negative bacteria (Agersø \& Sandvang, 2005). Significant correlations between Intl1 and tet $\mathrm{O}$, tet $\mathrm{W}$ and sul3 were also found in fish tanks water with exposure to antibiotics (He et al., 2017). Such correlation indicated that these ARGs could have been on conjugative plasmids and 
could transfer among microbes using the class 1 integron as a carrier, which means that Intl1 plays an important role in the propagation of ARGs (Agersø \& Sandvang, 2005; Bennett, 2008; Wang et al., 2017a).

The relationship between the abundance of Intl 1 and the concentration of antibiotics has been studied previously (Chen et al., 2015b; Subirats et al., 2018). Chen et al. (2015b) demonstrated that the relative abundance of Intl 1 was significantly correlated with the total concentration of antibiotics, and the higher concentration of antibiotics resulted in the greater abundance of Intl 1 gene in both water and sediment samples. Subirats et al. (2018) also indicated that bacterial communities exposed to antibiotics resulted in higher copy numbers of sul 1 and Intl 1 genes than those not exposed. To some extent, the increase in the relative abundance of sul1 may be related to integron mobilization since this gene is usually linked to class 1 integrons (Gillings et al., 2015). This has been confirmed by He et al. (2017) and Rafraf et al. (2016), who found a significant correlation between sul 1 gene and Intll genes when exposed to sulfanilamide. Furthermore, the combination of antibiotics and metals in swine wastewater may provide a stronger selection for realized horizontal gene transfer among the microbial community than either alone (Baker-Austin et al., 2006; Zhu et al., 2013).

\subsection{Impacts of antibiotics on the host of ARGs in anaerobic processes}

In anaerobic processes, the bacterial community is significantly correlated to the fate of ARGs (Song et al., 2018; Tong et al., 2016). The bacterial community drives the distribution of ARGs during anaerobic digestion, and the level of ARGs in anaerobic processes is attributed to the survival or death of antibiotic resistant bacteria (Miller et al., 2016; Tao et al., 2016). Previous reports have conducted that most ARGs are carried by the function bacteria in anaerobic processes, which belong to the phylum of 
Bacteroidetes, Firmicutes, Proteobacteria, Actinobacteria and Spirochaetes (Aydin et al., 2015b; Forsberg et al., 2014; Resende et al., 2014; Sun et al., 2016). Hence, understanding the effect of antibiotics on the above functional bacteria is important for exploring the contribution of antibiotics to the fate of ARGs during anaerobic processes.

Bacteroidetes and Clostridium were the dominant hosts of tetracycline and sulfonamide resistance genes (Cetecioglu et al., 2016; Huang et al., 2015a; Sun et al., 2016). Specifically, Bacteroidetes were reported as the important hosts of tet $\mathrm{C}$, tet $\mathrm{M}, \operatorname{tet} \mathrm{Q}, \operatorname{tet} \mathrm{X}, \operatorname{erm} \mathrm{B}, \operatorname{erm} \mathrm{F}$ and $\operatorname{sul} 1$ (Tao et al., 2016). Aydin et al. (2015b) reported that almost $50 \%$ of the tetracycline resistance genes were located in the Clostridium genus. Their abundance were reported to be increased with the increase of TC and SMX concentrations in the anaerobic reactor (Cetecioglu et al., 2016; Xiong et al., 2017). Wang et al. (2017c) demonstrated that the presence of CTC in anaerobic reactors might promote the growth of species in family of Moraxellaceae and Pseudomonadaceae because of their strong resistance to CTC. It is known that Moraxellaceae and Pseudomonadaceae belong to the phylum of Proteobacteria, which had significant positive correlations with all ARGs and integrase genes, except for tet $\mathrm{W}$ and tetX (Sun et al. 2016, Wu et al. 2016). According to the report of Aydin et al. (2016), the number of Actinobacteria and Fusobacterium rose significantly with the increasing concentration of tetracycline and erythromycin, due to these phyla possibly acquiring antibiotic resistance and disseminating easily across the phylum. The authors also stated that the Acinetobacter-related populations and Bacteroidetes-related population in the anaerobic reactor played a functional role in the elimination of tetracycline and erythromycin antibiotics, and the acquisition of resistance genes. 
In the methanogenic phase, more diverse microbial community structure and more potential microbes could contain ARGs, because most of ARGs were observed to rebound significantly and increase in this stage (Wu et al., 2016). Therefore, an abundance of bacteria carrying ARGs might be increased with the addition of antibiotics into the anaerobic reactor. In other word, failure to maintain the stability of bacteria in anaerobic processes would result in the increasing occurrence of ARGs.

\section{Future perspectives}

It is clear that antibiotics in swine wastewater can affect the proliferation of ARGs in the anaerobic treatment process. Although most research studies have proved the positive correlation between antibiotics and their corresponding genes, other analyses still concluded differently due to the probable co-selection and/or cross-selection of other factors in swine wastewater (McKinney et al., 2010; Stepanauskas et al., 2006). In order to better characterize and understand their correlations to further explore the contribution of antibiotics to the fate of ARGs in the anaerobic treatment process, additional studies with respect to the selection pressure of present antibiotics in swine wastewater on the occurrence and accumulation of ARGs are needed. Similarly, HGT is an important mechanism for the transmission of ARGs among different microorganisms. Antibiotics have been believed to accelerate the horizontal transfer of ARGs (Aydin et al., 2015b; Li et al., 2009). However, it is still necessary to study the effect of antibiotics on mechanisms of HGT in the future.

In anaerobic treatment processes, microorganisms show an important responsibility for the fate of ARGs, but it is very difficult to clearly understand their relationship with ARGs. The microbial community in anaerobic treatment processes is very complex and most microorganisms are uncultivated. As well, the microbial structure could vary 
depending on different operation conditions of the anaerobic treatment process (Tao et al., 2016; Tian et al., 2016). Thus, to further clarify the correlation between ARGs and microbial communities and provide more information on the treatment of ARGs by anaerobic treatment processes, it is necessary to learn more about ARGs profiles as well as microbial community composition during the swine wastewater treatment process.

Currently, metagenomic sequencing or qPCR were usually used to detect ARGs in the environment (Guo et al., 2017; He et al., 2016; Tao et al., 2014). However, as reported by Tian et al. (2016), metagenomic sequencing or the qPCR method cannot distinguish ARGs from live or dead cells in anaerobic treatment processes, which could result in partially distorting the temporal and spatial patterns of the detected ARGs. In order to evaluate the removal efficiency of ARGs in a treatment process and their abundance in different environmental media, the more accurate method need to develop. In addition, it is difficult to evaluate whether the treatment technology is safe for the treatment of ARGs because there is no standard for their discharge, although they were proposed as emerging contaminants more than 10 years ago (Pruden et al., 2006). Therefore, more and suitable studies on the risk of ARGs are needed to draft a discharge standard for ARGs in swine wastewater treatment plants in future research. Finally, as reported by Lopatkin et al. (2017), ARGs could act to stabilize and persist for many years in the environment even in the absence of antibiotics. That is why treatment technologies are urgently requires to remove antibiotic and ARGs effectively from q much higher than that in drinking water sources and lakes. The removal or enrichment of ARGs in anaerobic treatment processes is difficult to give a general conclusion. Antibiotics in swine wastewater showed a positive effect on the abundance of ARGs, the transfer of ARGs, and the abundance of bacteria carrying ARGs and Intll. 
Understanding the contribution of antibiotics to the proliferation of ARGs is significant to control their dissemination in the environment. Further studies are necessary to explore the correlation among antibiotics, ARGs and microbial communities.

\section{Acknowledgement}

This research was supported by the Centre for Technology in Water and Wastewater, University of Technology, Sydney, Australia (UTS, RIA NGO) and in part by grants from the Korea Ministry of Environment as an "Algae Monitoring \& Removing Utilization Technology" (Project No. 2015001790001) and Korean Ministry of Environment as a "Global Top Project”, Project No. 201600220005.

\section{References}

1. Agersø, Y., Sandvang, D., 2005. Class 1 integrons and tetracycline resistance genes in Alcaligenes, Arthrobacter, and Pseudomonas spp. isolated from pigsties and manured soil. Appl. Environ. Microbiol. 71 (12), 7941-7947.

2. Akyol, Ç., Aydin, S., Ince, O., Ince, B., 2016. A comprehensive microbial insight into single-stage and two-stage anaerobic digestion of oxytetracycline-medicated cattle manure. Chem. Eng. J. 303, 675-684.

3. Allen, H.K., Donato, J., Wang, H.H., Cloud-Hansen, K.A., Davies, J., Handelsman, J., 2010. Call of the wild: antibiotic resistance genes in natural environments. Nat. Rev. Microbiol. 8 (4), 251-259.

4. Álvarez, M., Gómez, L., Ulloa, R., Deive, F., Sanromán, M., Rodríguez, A., 2016. Antibiotics in swine husbandry effluents: Laying the foundations for their efficient removal with a biocompatible ionic liquid. Chem. Eng. J. 298, 10-16. 
5. Aminov, R.I., 2011. Horizontal gene exchange in environmental microbiota. Front. Microbiol. 2, 158.

6. Apley, M.D., Bush, E.J., Morrison, R.B., Singer, R.S., Snelson, H., 2012. Use estimates of in-feed antimicrobials in swine production in the United States. Foodborne Pathog. Dis. 9 (3), 272-279.

7. Arabi, H., Pakzad, I., Nasrollahi, A., Hosainzadegan, H., Jalilian, F. A., Taherikalani, M., Samadi, N., Sefidan, A. M., 2015. Sulfonamide resistance genes (sul) $\mathrm{M}$ in extended Spectrum Beta lactamase (ESBL) and non-ESBL producing Escherichia Coli isolated from Iranian hospitals. Jundishapur J. Microbiol. 8 (7), e19961.

8. Aydin, S., Ince, B., Ince, O., 2015a. Application of real-time PCR to determination of combined effect of antibiotics on Bacteria, Methanogenic Archaea, Archaea in anaerobic sequencing batch reactors. Water Res. 76, 88-98.

9. Aydin, S., Ince, B., Ince, O., 2016. Assessment of anaerobic bacterial diversity and its effects on anaerobic system stability and the occurrence of antibiotic resistance genes. Bioresour. Technol. 207, 332-338.

10. Aydin, S., Ince, B., Ince, O., 2015b. Development of antibiotic resistance genes in microbial communities during long-term operation of anaerobic reactors in the treatment of pharmaceutical wastewater. Water Res. 83, 337-344.

11. Baker-Austin, C., Wright, M.S., Stepanauskas, R., McArthur, J., 2006. Coselection of antibiotic and metal resistance. Trends Microbiol. 14 (4), 176-182.

12. Balcazar, J.L., 2014. Bacteriophages as vehicles for antibiotic resistance genes in the environment. PLoS Path. 10 (7), e1004219.

13. Beaber, J.W., Hochhut, B., Waldor, M.K., 2004. SOS response promotes horizontal dissemination of antibiotic resistance genes. Nat. 427 (6969), 72-74. 
14. Ben, W., Wang, J., Pan, X., Qiang, Z., 2017. Dissemination of antibiotic resistance genes and their potential removal by on-farm treatment processes in nine swine feedlots in Shandong Province, China. Chemosphere 167, 262-268.

15. Bennett, P., 2008. Plasmid encoded antibiotic resistance: Acquisition and transfer of antibiotic resistance genes in bacteria. Br. J. Pharmacol. 153 (S1), S347-57. 16. Berglund, B., 2015. Environmental dissemination of antibiotic resistance genes and correlation to anthropogenic contamination with antibiotics. Infection Ecology \& Epidemiology, 5 (1), Article: 28564.

17. Billington, S.J., Songer, J.G., Jost, B.H., 2002. Widespread distribution of a Tet W determinant among tetracycline-resistant isolates of the animal pathogen Arcanobacterium pyogenes. Antimicrob. Agents Chemother. 46 (5), 1281-1287.

18. Cetecioglu, Z., Ince, B., Orhon, D., Ince, O., 2016. Anaerobic sulfamethoxazole degradation is driven by homoacetogenesis coupled with hydrogenotrophic methanogenesis. Water Res. 90, 79-89.

19. Chee-Sanford, J.C., Mackie, R.I., Koike, S., Krapac, I.G., Lin, Y.-F., Yannarell, A.C., Maxwell, S., Aminov, R.I., 2009. Fate and transport of antibiotic residues and antibiotic resistance genes following land application of manure waste. J. Environ. Qual. 38 (3), 1086-1108.

20. Chen, B., Hao, L., Guo, X., Wang, N., Ye, B., 2015a. Prevalence of antibiotic resistance genes of wastewater and surface water in livestock farms of Jiangsu Province, China. Environ. Sci. Pollut. Res. 22 (18), 13950-13959.

21. Chen, B., Liang, X., Nie, X., Huang, X., Zou, S., Li, X., 2015b. The role of class I integrons in the dissemination of sulfonamide resistance genes in the Pearl River and Pearl River Estuary, South China. J. Hazard. Mater. 282, 61-67. 
22. Chen, H., Jing, L., Teng, Y., Wang, J., 2018. Multimedia fate modeling and risk assessment of antibiotics in a water-scarce megacity. J. Hazard. Mater. 348, 75-83.

23. Chen, I., Dubnau, D., 2004. DNA uptake during bacterial transformation. Nat. Rev. Microbiol. 2 (3), 241.

24. Chen, J., Michel, F.C., Sreevatsan, S., Morrison, M., Yu, Z., 2010. Occurrence and persistence of erythromycin resistance genes (erm) and tetracycline resistance genes (tet) in waste treatment systems on swine farms. Microb. Ecol. 60 (3), 479-486.

25. Cheng, D.L., Ngo, H.H., Guo, W.S., Chang, S.W., Nguyen, D.D., Kumar, S.M., Du, B., Wei, Q., Wei, D., 2018a. Problematic effects of antibiotics on anaerobic treatment of swine wastewater. Bioresour. Technol. 263, 642-653.

26. Cheng, D.L., Ngo, H.H., Guo, W.S., Liu, Y.W., Zhou, J.L., Chang, S.W., Nguyen, D.D., Bui, X.T., Zhang, X.B., 2018b. Bioprocessing for elimination antibiotics and hormones from swine wastewater. Sci. Total Environ. 621, 1664-1682.

27. Cheng, W., Chen, H., Su, C., Yan, S., 2013. Abundance and persistence of antibiotic resistance genes in livestock farms: a comprehensive investigation in eastern China. Environ. Int. 61, 1-7.

28. Cheng, W., Li, J., Wu, Y., Xu, L., Su, C., Qian, Y., Zhu, Y.-G., Chen, H., 2016. Behavior of antibiotics and antibiotic resistance genes in eco-agricultural system: a case study. J. Hazard. Mater. 304, 18-25.

29. Chopra, I., Roberts, M., 2001. Tetracycline antibiotics: mode of action, applications, molecular biology, and epidemiology of bacterial resistance. Microbiol. Mol. Biol. Rev. 65 (2), 232-260.

30. Diehl, D.L., LaPara, T.M., 2010. Effect of temperature on the fate of genes encoding tetracycline resistance and the integrase of class 1 integrons within anaerobic 
and aerobic digesters treating municipal wastewater solids. Environ. Sci. Technol. 44 (23), 9128-9133.

31. Forsberg, K.J., Patel, S., Gibson, M.K., Lauber, C.L., Knight, R., Fierer, N., Dantas, G., 2014. Bacterial phylogeny structures soil resistomes across habitats. Nat. 509 (7502), 612-616.

32. Frost, L.S., Leplae, R., Summers, A.O., Toussaint, A., 2005. Mobile genetic elements: the agents of open source evolution. Nat. Rev. Microbiol. 3 (9), 722-732. 33. Furuya, E.Y., Lowy, F.D., 2006. Antimicrobial-resistant bacteria in the community setting. Nat. Rev. Microbiol. 4 (1), 36-45.

34. Gao, P., Mao, D., Luo, Y., Wang, L., Xu, B., Xu, L., 2012a. Occurrence of sulfonamide and tetracycline-resistant bacteria and resistance genes in aquaculture environment. Water Res. 46 (7), 2355-2364.

35. Gao, P., Munir, M., Xagoraraki, I., 2012b. Correlation of tetracycline and sulfonamide antibiotics with corresponding resistance genes and resistant bacteria in a conventional municipal wastewater treatment plant. Sci. Total Environ. 421, 173-183. 36. Ghosh, S., LaPara, T.M., 2007. The effects of subtherapeutic antibiotic use in farm animals on the proliferation and persistence of antibiotic resistance among soil bacteria. ISME J. 1 (3), 191-203.

37. Ghosh, S., Ramsden, S.J., LaPara, T.M., 2009. The role of anaerobic digestion in controlling the release of tetracycline resistance genes and class 1 integrons from municipal wastewater treatment plants. Appl. Microbiol. Biotechnol. 84 (4), 791-796. 38. Gillings, M.R., Gaze, W.H., Pruden, A., Smalla, K., Tiedje, J.M., Zhu, Y.-G., 2015. Using the class 1 integron-integrase gene as a proxy for anthropogenic pollution. ISME J. 9 (6), 1269-1279. 
39. Guerin, É., Cambray, G., Sanchez-Alberola, N., Campoy, S., Erill, I., Da Re, S., Gonzalez-Zorn, B., Barbé, J., Ploy, M.-C., Mazel, D., 2009. The SOS response controls integron recombination. Sci. 324 (5930), 1034-1034.

40. Gullberg, E., Cao, S., Berg, O.G., Ilbäck, C., Sandegren, L., Hughes, D., Andersson, D.I., 2011. Selection of resistant bacteria at very low antibiotic concentrations. PLoS Path. 7 (7), e1002158.

41. Guo, J., Li, J., Chen, H., Bond, P.L., Yuan, Z., 2017. Metagenomic analysis reveals wastewater treatment plants as hotspots of antibiotic resistance genes and mobile genetic elements. Water Res. 123, 468-478.

42. He, L.-Y., Ying, G.-G., Liu, Y.-S., Su, H.-C., Chen, J., Liu, S.-S., Zhao, J.-L., 2016. Discharge of swine wastes risks water quality and food safety: Antibiotics and antibiotic resistance genes from swine sources to the receiving environments. Environ. Int. 92, 210-219.

43. He, X., Xu, Y., Chen, J., Ling, J., Li, Y., Huang, L., Zhou, X., Zheng, L., Xie, G., 2017. Evolution of corresponding resistance genes in the water of fish tanks with multiple stresses of antibiotics and heavy metals. Water Res. 124, 39-48.

44. Hershberg, R., 2017. Antibiotic-Independent Adaptive Effects of Antibiotic Resistance Mutations. Trends Genet. 33 (8), 521-528.

45. Hsu, J.T., Chen, C.-Y., Young, C.-W., Chao, W.-L., Li, M.-H., Liu, Y.-H., Lin, C.-M., Ying, C., 2014. Prevalence of sulfonamide-resistant bacteria, resistance genes and integron-associated horizontal gene transfer in natural water bodies and soils adjacent to a swine feedlot in northern Taiwan. J. Hazard. Mater. 277, 34-43. 
46. Huang, M., Qi, F., Wang, J., Xu, Q., Lin, L., 2015a. Changes of bacterial diversity and tetracycline resistance in sludge from AAO systems upon exposure to tetracycline pressure. J. Hazard. Mater. 298, 303-309.

47. Huang, X., Liu, C., Li, K., Su, J., Zhu, G., Liu, L., 2015b. Performance of vertical up-flow constructed wetlands on swine wastewater containing tetracyclines and tet genes. Water Res. 70, 109-117.

48. Huang, X., Zheng, J., Liu, C., Liu, L., Liu, Y., Fan, H., 2017. Removal of antibiotics and resistance genes from swine wastewater using vertical flow constructed wetlands: Effect of hydraulic flow direction and substrate type. Chem. Eng. J. 308, 692699.

49. Hultman, J., Tamminen, M., Pärnänen, K., Cairns, J., Karkman, A. and Virta, M., 2018. Host range of antibiotic resistance genes in wastewater treatment plant influent and effluent. FEMS Microbiol. Ecol. 94 (4), p.fiy038

50. Jechalke, S., Heuer, H., Siemens, J., Amelung, W., Smalla, K., 2014. Fate and effects of veterinary antibiotics in soil. Trends Microbiol. 22 (9), 536-545.

51. Ji, X., Shen, Q., Liu, F., Ma, J., Xu, G., Wang, Y., Wu, M., 2012. Antibiotic resistance gene abundances associated with antibiotics and heavy metals in animal manures and agricultural soils adjacent to feedlots in Shanghai; China. J. Hazard. Mater. $235,178-185$.

52. Jia, S., Zhang, X.-X., Miao, Y., Zhao, Y., Ye, L., Li, B., Zhang, T., 2017. Fate of antibiotic resistance genes and their associations with bacterial community in livestock breeding wastewater and its receiving river water. Water Res. 124, 259-268. 
53. Jiang, L., Hu, X., Xu, T., Zhang, H., Sheng, D., Yin, D., 2013. Prevalence of antibiotic resistance genes and their relationship with antibiotics in the Huangpu River and the drinking water sources, Shanghai, China. Sci. Total Environ. 458, 267-272. 54. Joy, S.R., Li, X., Snow, D.D., Gilley, J.E., Woodbury, B., Bartelt-Hunt, S.L., 2014. Fate of antimicrobials and antimicrobial resistance genes in simulated swine manure storage. Sci. Total Environ. 481, 69-74.

55. Ju, F., Beck, K., Yin, X., Maccagnan, A., McArdell, C.S., Singer, H.P., Johnson, D.R., Zhang, T. and Bürgmann, H., 2019. Wastewater treatment plant resistomes are shaped by bacterial composition, genetic exchange, and upregulated expression in the effluent microbiomes. ISME J. 13 (2), p.346.

56. Jutkina, J., Marathe, N., Flach, C.-F., Larsson, D., 2018. Antibiotics and common antibacterial biocides stimulate horizontal transfer of resistance at low concentrations. Sci. Total Environ. 616, 172-178.

57. Jutkina, J., Rutgersson, C., Flach, C.-F., Larsson, D.J., 2016. An assay for determining minimal concentrations of antibiotics that drive horizontal transfer of resistance. Sci. Total Environ. 548, 131-138.

58. Koike, S., Krapac, I., Oliver, H., Yannarell, A., Chee-Sanford, J., Aminov, R., Mackie, R., 2007. Monitoring and source tracking of tetracycline resistance genes in lagoons and groundwater adjacent to swine production facilities over a 3-year period. Appl. Environ. Microbiol. 73 (15), 4813-4823.

59. Landers, T.F., Cohen, B., Wittum, T.E., Larson, E.L., 2012. A review of antibiotic use in food animals: perspective, policy, and potential. Public Health Rep. $127(1), 4-22$. 
60. Lee, J.Y., Monk, I.R., da Silva, A.G., Seemann, T., Chua, K.Y., Kearns, A., Hill, R., Woodford, N., Bartels, M.D., Strommenger, B., 2018. Global spread of three multidrug-resistant lineages of Staphylococcus epidermidis. Nat. Microbiol. 3, 11751185.

61. Levy, S.B., 2002. Factors impacting on the problem of antibiotic resistance. J. Antimicrob. Chemother. 49 (1), 25-30.

62. Li, D., Yang, M., Hu, J., Zhang, J., Liu, R., Gu, X., Zhang, Y., Wang, Z., 2009. Antibiotic - resistance profile in environmental bacteria isolated from penicillin production wastewater treatment plant and the receiving river. Environ. Microbiol. 11 (6), 1506-1517.

63. Li, D., Yu, T., Zhang, Y., Yang, M., Li, Z., Liu, M., Qi, R., 2010. Antibiotic resistance characteristics of environmental bacteria from an oxytetracycline production wastewater treatment plant and the receiving river. Appl. Environ. Microbiol. 76 (11), $3444-3451$.

64. Li, H., Li, B., Ma, J., Ye, J., Guo, P., Li, L., 2018a. Fate of antibiotic-resistant bacteria and antibiotic resistance genes in the electrokinetic treatment of antibioticpolluted soil. Chem. Eng. J. 337, 584-594.

65. Li, J., 2017. Current status and prospects for in-feed antibiotics in the different stages of pork production-A review. Asian-Australas J. Anim. Sci. 30 (12), 1667. 66. Li, J., Cheng, W., Xu, L., Strong, P., Chen, H., 2015. Antibiotic-resistant genes and antibiotic-resistant bacteria in the effluent of urban residential areas, hospitals, and a municipal wastewater treatment plant system. Environ. Sci. Pollut. Res. 22 (6), 45874596. 
67. Li, X., Liu, C., Chen, Y., Huang, H., Ren, T., 2018b. Antibiotic residues in liquid manure from swine feedlot and their effects on nearby groundwater in regions of North China. Environ. Sci. Pollut. Res. 1-11.

68. Liu, M., Zhang, Y., Yang, M., Tian, Z., Ren, L., Zhang, S., 2012. Abundance and distribution of tetracycline resistance genes and mobile elements in an oxytetracycline production wastewater treatment system. Environ. Sci. Technol. 46 (14), 7551-7557.

69. Looft, T., Johnson, T.A., Allen, H.K., Bayles, D.O., Alt, D.P., Stedtfeld, R.D., Sul, W.J., Stedtfeld, T.M., Chai, B., Cole, J.R., 2012. In-feed antibiotic effects on the swine intestinal microbiome. Proc. Natl. Acad. Sci. 109 (5), 1691-1696.

70. Lopatkin, A.J., Huang, S., Smith, R.P., Srimani, J.K., Sysoeva, T.A., Bewick, S., Karig, D.K., You, L., 2016a. Antibiotics as a selective driver for conjugation dynamics. Nat. Microbiol. 1 (6), Article number: 16044.

71. Lopatkin, A.J., Meredith, H.R., Srimani, J.K., Pfeiffer, C., Durrett, R., You, L., 2017. Persistence and reversal of plasmid-mediated antibiotic resistance. Nat. Commun. $8(1), 1689$.

72. Lopatkin, A.J., Sysoeva, T.A., You, L., 2016b. Dissecting the effects of antibiotics on horizontal gene transfer: analysis suggests a critical role of selection dynamics. Bioessays 38 (12), 1283-1292.

73. López, E., Elez, M., Matic, I., Blázquez, J., 2007. Antibiotic - mediated recombination: Ciprofloxacin stimulates SOS - independent recombination of divergent sequences in Escherichia coli. Mol. Microbiol. 64 (1), 83-93.

74. Lu, Y., Zeng, J., Wang, L., Lan, K., Shunmei, E., Wang, L., Xiao, Q., Luo, Q., Huang, X., Huang, B., 2017. Antibiotics Promote Escherichia coli-Pseudomonas 
aeruginosa Conjugation through Inhibiting Quorum Sensing. Antimicrob. Agents Chemother. 61 (12), e01284-17.

75. Luo, G., Li, B., Li, L.-G., Zhang, T., Angelidaki, I., 2017. Antibiotic Resistance Genes and Correlations with Microbial Community and Metal Resistance Genes in FullScale Biogas Reactors As Revealed by Metagenomic Analysis. Environ. Sci. Technol. $51(7), 4069-4080$.

76. Lupo, A., Coyne, S., Berendonk, T.U., 2012. Origin and evolution of antibiotic resistance: the common mechanisms of emergence and spread in water bodies. Front. Microbiol. 3, 18.

77. Ma, Y., Wilson, C.A., Novak, J.T., Riffat, R., Aynur, S., Murthy, S., Pruden, A., 2011. Effect of various sludge digestion conditions on sulfonamide, macrolide, and tetracycline resistance genes and class I integrons. Environ. Sci. Technol. 45 (18), $7855-$ 7861.

78. Ma, Z., Wu, H.H., Zhang, K.S., Xu, X.K., Wang, C., Zhu, W.J., Wu, W.X., 2018. Long-term low dissolved oxygen accelerates the removal of antibiotics and antibiotic resistance genes in swine wastewater treatment. Chem. Eng. J. 334, 630-637. 79. McKinney, C.W., Loftin, K.A., Meyer, M.T., Davis, J.G., Pruden, A., 2010. Tet and sul antibiotic resistance genes in livestock lagoons of various operation type, configuration, and antibiotic occurrence. Environ. Sci. Technol. 44 (16), 6102-6109. 80. Miller, J.H., Novak, J.T., Knocke, W.R., Pruden, A., 2016. Survival of antibiotic resistant bacteria and horizontal gene transfer control antibiotic resistance gene content in anaerobic digesters. Front. Microbiol. 7, 263. 
81. Miller, J.H., Novak, J.T., Knocke, W.R., Young, K., Hong, Y., Vikesland, P.J., Hull, M.S., Pruden, A., 2013. Effect of silver nanoparticles and antibiotics on antibiotic resistance genes in anaerobic digestion. Water Environ. Res. 85 (5), 411-421.

82. Mohring, S.A., Strzysch, I., Fernandes, M.R., Kiffmeyer, T.K., Tuerk, J., Hamscher, G., 2009. Degradation and elimination of various sulfonamides during anaerobic fermentation: a promising step on the way to sustainable pharmacy? Environ. Sci. Technol. 43 (7), 2569-2574.

83. Organization, W.H. 2014. Antimicrobial resistance: global report on surveillance. World Health Organization.

84. Peak, N., Knapp, C.W., Yang, R.K., Hanfelt, M.M., Smith, M.S., Aga, D.S., Graham, D.W., 2007. Abundance of six tetracycline resistance genes in wastewater lagoons at cattle feedlots with different antibiotic use strategies. Environ. Microbiol. 9 (1), 143-151.

85. Pruden, A., Pei, R., Storteboom, H., Carlson, K.H., 2006. Antibiotic resistance genes as emerging contaminants: studies in northern Colorado. Environ. Sci. Technol. 40 (23), 7445-7450.

86. Pu, C., Liu, H., Ding, G., Sun, Y., Yu, X., Chen, J., Ren, J., Gong, X., 2018. Impact of direct application of biogas slurry and residue in fields: In situ analysis of antibiotic resistance genes from pig manure to fields. J. Hazard. Mater. 344, 441-449. 87. Qian, X., Sun, W., Gu, J., Wang, X.-J., Sun, J.-J., Yin, Y.-N., Duan, M.-L., 2016. Variable effects of oxytetracycline on antibiotic resistance gene abundance and the bacterial community during aerobic composting of cow manure. J. Hazard. Mater. $315,61-69$. 
88. Rafraf, I.D., Lekunberri, I., Sànchez-Melsió, A., Aouni, M., Borrego, C.M., Balcázar, J.L., 2016. Abundance of antibiotic resistance genes in five municipal wastewater treatment plants in the Monastir Governorate, Tunisia. Environ. Pollut. 219, $353-358$.

89. Resende, J.A., Diniz, C., Silva, V., Otenio, M., Bonnafous, A., Arcuri, P., Godon, J.J., 2014. Dynamics of antibiotic resistance genes and presence of putative pathogens during ambient temperature anaerobic digestion. J. Appl. Microbiol. 117 (6), 1689-1699.

90. Sarmah, A.K., Meyer, M.T., Boxall, A.B., 2006. A global perspective on the use, sales, exposure pathways, occurrence, fate and effects of veterinary antibiotics (VAs) in the environment. Chemosphere 65 (5), 725-759.

91. Scornec, H., Bellanger, X., Guilloteau, H., Groshenry, G., Merlin, C., 2017. Inducibility of Tn 916 conjugative transfer in Enterococcus faecalis by subinhibitory concentrations of ribosome-targeting antibiotics. J. Antimicrob. Chemother. 72 (10), $2722-2728$.

92. Selvam, A., Xu, D., Zhao, Z., Wong, J.W., 2012. Fate of tetracycline, sulfonamide and fluoroquinolone resistance genes and the changes in bacterial diversity during composting of swine manure. Bioresour. Technol. 126, 383-390.

93. Shi, Z.-J., Hu, H.-Y., Shen, Y.-Y., Xu, J.-J., Shi, M.-L., Jin, R.-C., 2017. Longterm effects of oxytetracycline (OTC) on the granule-based anammox: Process performance and occurrence of antibiotic resistance genes. Biochem. Eng. J. 127, 110 118.

94. Skouteris, G., Hermosilla, D., López, P., Negro, C., Blanco, Á., 2012. Anaerobic membrane bioreactors for wastewater treatment: a review. Chem. Eng. J. 198, 138-148. 
95. Smith, M.S., Yang, R.K., Knapp, C.W., Niu, Y., Peak, N., Hanfelt, M.M., Galland, J.C., Graham, D.W., 2004. Quantification of tetracycline resistance genes in feedlot lagoons by real-time PCR. Appl. Environ. Microbiol. 70 (12), 7372-7377.

96. Song, H.-L., Li, H., Zhang, S., Yang, Y.-L., Zhang, L.-M., Xu, H., Yang, X.-L., 2018. Fate of sulfadiazine and its corresponding resistance genes in up-flow microbial fuel cell coupled constructed wetlands: Effects of circuit operation mode and hydraulic retention time. Chem. Eng. J. 350, 920-929.

97. Song, L., Li, L., Yang, S., Lan, J., He, H., McElmurry, S.P., Zhao, Y., 2016. Sulfamethoxazole, tetracycline and oxytetracycline and related antibiotic resistance genes in a large-scale landfill, China. Sci. Total Environ. 551, 9-15.

98. Sørensen, S.J., Bailey, M., Hansen, L.H., Kroer, N., Wuertz, S., 2005. Studying plasmid horizontal transfer in situ: a critical review. Nat. Rev. Microbiol. 3 (9), 700710.

99. Stepanauskas, R., Glenn, T.C., Jagoe, C.H., Tuckfield, R.C., Lindell, A.H., King, C.J., McArthur, J., 2006. Coselection for microbial resistance to metals and antibiotics in freshwater microcosms. Environ. Microbiol. 8 (9), 1510-1514.

100. Stevens, A., Shoemaker, N., Li, L.-Y., Salyers, A.A., 1993. Tetracycline regulation of genes on Bacteroides conjugative transposons. J. Bacteriol. 175 (19), 6134-6141.

101. Su, H.-C., Liu, Y.-S., Pan, C.-G., Chen, J., He, L.-Y., Ying, G.-G., 2018.

Persistence of antibiotic resistance genes and bacterial community changes in drinking water treatment system: From drinking water source to tap water. Sci. Total Environ. $616,453-461$. 
102. Subirats, J., Timoner, X., Sànchez-Melsió, A., Balcázar, J.L., Acuña, V., Sabater, S., Borrego, C.M., 2018. Emerging contaminants and nutrients synergistically affect the spread of class 1 integron-integrase (intI1) and sul1 genes within stable streambed bacterial communities. Water Res. 138, 77-85.

103. Sui, Q., Liu, C., Dong, H., Zhu, Z., 2014. Effect of ammonium nitrogen concentration on the ammonia-oxidizing bacteria community in a membrane bioreactor for the treatment of anaerobically digested swine wastewater. J. Biosci. Bioeng. 118 (3), 277-283.

104. Sui, Q., Zhang, J., Chen, M., Tong, J., Wang, R., Wei, Y., 2016. Distribution of antibiotic resistance genes (ARGs) in anaerobic digestion and land application of swine wastewater. Environ. Pollut. 213, 751-759.

105. Sui, Q., Zhang, J., Tong, J., Chen, M., Wei, Y., 2017. Seasonal variation and removal efficiency of antibiotic resistance genes during wastewater treatment of swine farms. Environ. Sci. Pollut. Res. 24 (10), 9048-9057.

106. Sun, W., Qian, X., Gu, J., Wang, X.-J., Duan, M.-L., 2016. Mechanism and effect of temperature on variations in antibiotic resistance genes during anaerobic digestion of dairy manure. Sci. Rep. 6, Article: 30237.

107. Tao, C.-W., Hsu, B.-M., Ji, W.-T., Hsu, T.-K., Kao, P.-M., Hsu, C.-P., Shen, S.M., Shen, T.-Y., Wan, T.-J., Huang, Y.-L., 2014. Evaluation of five antibiotic resistance genes in wastewater treatment systems of swine farms by real-time PCR. Sci. Total Environ. 496, 116-121.

108. Tao, W., Zhang, X.-X., Zhao, F., Huang, K., Ma, H., Wang, Z., Ye, L., Ren, H., 2016. High levels of antibiotic resistance genes and their correlations with bacterial 
community and mobile genetic elements in pharmaceutical wastewater treatment bioreactors. PLoS ONE 11 (6), Article: 0156854.

109. Tian, Z., Zhang, Y., Yu, B., Yang, M., 2016. Changes of resistome, mobilome and potential hosts of antibiotic resistance genes during the transformation of anaerobic digestion from mesophilic to thermophilic. Water Res. 98, 261-269.

110. Tong, J., Liu, J., Zheng, X., Zhang, J., Ni, X., Chen, M., Wei, Y., 2016. Fate of antibiotic resistance bacteria and genes during enhanced anaerobic digestion of sewage sludge by microwave pretreatment. Bioresour. Technol. 217, 37-43.

111. Úbeda, C., Maiques, E., Knecht, E., Lasa, Í., Novick, R.P., Penadés, J.R., 2005. Antibiotic - induced SOS response promotes horizontal dissemination of pathogenicity island - encoded virulence factors in Staphylococci. Mol. Microbiol. 56 (3), 836-844. 112. Wang, J., Ben, W., Yang, M., Zhang, Y., Qiang, Z., 2016a. Dissemination of veterinary antibiotics and corresponding resistance genes from a concentrated swine feedlot along the waste treatment paths. Environ. Int. 92, 317-323.

113. Wang, M., Shen, W., Yan, L., Wang, X.-H., Xu, H., 2017a. Stepwise impact of urban wastewater treatment on the bacterial community structure, antibiotic contents, and prevalence of antimicrobial resistance. Environ. Pollut. 231, 1578-1585.

114. Wang, R., Chen, M., Feng, F., Zhang, J., Sui, Q., Tong, J., Wei, Y., Wei, D., 2017b. Effects of chlortetracycline and copper on tetracyclines and copper resistance genes and microbial community during swine manure anaerobic digestion. Bioresour. Technol. 238, 57-69.

115. Wang, R., Zhang, J., Liu, J., Yu, D., Zhong, H., Wang, Y., Chen, M., Tong, J., Wei, Y., 2017c. Effects of chlortetracycline, $\mathrm{Cu}$ and their combination on the 
performance and microbial community dynamics in swine manure anaerobic digestion. J. Environ. Sci. 67, 206-215.

116. Wang, S., Fan, C., Low, A., He, J., 2014a. Comparison of microbial communities in sequencing batch reactors (SBRs) exposed to trace erythromycin and erythromycin-H2O. Appl. Microbiol. Biotechnol. 98 (6), 2667-2673.

117. Wang, W., Guo, Q., Xu, X., Sheng, Z.-k., Ye, X., Wang, M., 2014b. High-level tetracycline resistance mediated by efflux pumps Tet (A) and Tet (A)-1 with two start codons. J. Med. Microbiol. 63 (11), 1454-1459.

118. Wang, X., Pan, H., Gu, J., Qian, X., Gao, H., Qin, Q., 2016b. Effects of oxytetracycline on archaeal community, and tetracycline resistance genes in anaerobic co-digestion of pig manure and wheat straw. Environ. Technol. 37 (24), 3177-3185.

119. Wozniak, R.A., Waldor, M.K., 2010. Integrative and conjugative elements: mosaic mobile genetic elements enabling dynamic lateral gene flow. Nat. Rev. Microbiol. 8 (8), 552-563.

120. Wu, D., Huang, Z., Yang, K., Graham, D., Xie, B., 2015. Relationships between antibiotics and antibiotic resistance gene levels in municipal solid waste leachates in Shanghai, China. Environ. Sci. Technol. 49 (7), 4122-4128.

121. Wu, N., Qiao, M., Zhang, B., Cheng, W.-D., Zhu, Y.-G., 2010. Abundance and diversity of tetracycline resistance genes in soils adjacent to representative swine feedlots in China. Environ. Sci. Technol. 44 (18), 6933-6939.

122. Wu, Y., Cui, E., Zuo, Y., Cheng, W., Rensing, C., Chen, H., 2016. Influence of two-phase anaerobic digestion on fate of selected antibiotic resistance genes and class I integrons in municipal wastewater sludge. Bioresour. Technol. 211, 414-421. 
123. Xie, W.-Y., Yang, X.-P., Li, Q., Wu, L.-H., Shen, Q.-R., Zhao, F.-J., 2016.

Changes in antibiotic concentrations and antibiotic resistome during commercial composting of animal manures. Environ. Pollut. 219, 182-190.

124. Xiong, Y., Harb, M., Hong, P.-Y., 2017. Performance and microbial community variations of anaerobic digesters under increasing tetracycline concentrations. Appl. Microbiol. Biotechnol. 101 (13), 5505-5517.

125. Yang, W., Moore, I.F., Koteva, K.P., Bareich, D.C., Hughes, D.W., Wright, G.D., 2004. TetX is a flavin-dependent monooxygenase conferring resistance to tetracycline antibiotics. J. Biol. Chem. 279 (50), 52346-52352.

126. Yang, Y., Li, B., Zou, S., Fang, H.H., Zhang, T., 2014. Fate of antibiotic resistance genes in sewage treatment plant revealed by metagenomic approach. Water Res. 62, 97-106.

127. Yang, Y., Song, W., Lin, H., Wang, W., Du, L., Xing, W., 2018. Antibiotics and antibiotic resistance genes in global lakes: A review and meta-analysis. Environ. Int. $116,60-73$.

128. Yin, Y., Gu, J., Wang, X., Song, W., Zhang, K., Sun, W., Zhang, X., Zhang, Y., Li, H., 2017. Effects of copper addition on copper resistance, antibiotic resistance genes, and intl1 during swine manure composting. Front. Microbiol. 8, 344.

129. Yuan, Q.-B., Zhai, Y.-F., Mao, B.-Y., Hu, N., 2018. Antibiotic resistance genes and intI1 prevalence in a swine wastewater treatment plant and correlation with metal resistance, bacterial community and wastewater parameters. Ecotoxicol. Environ. Saf. $161,251-259$. 
130. Zarei-Baygi, A., Harb, M., Wang, P., Stadler, L.B., Smith, A., 2019. Evaluating Antibiotic Resistance Gene Correlations with Antibiotic Exposure Conditions in Anaerobic Membrane Bioreactors. Environ. Sci. Technol. 53 (7), 3599-3609.

131. Zhang, J., Chen, M., Sui, Q., Wang, R., Tong, J., Wei, Y., 2016. Fate of antibiotic resistance genes and its drivers during anaerobic co-digestion of food waste and sewage sludge based on microwave pretreatment. Bioresour. Technol. 217, 28-36. 132. Zhang, L., Levy, K., Trueba, G., Cevallos, W., Trostle, J., Foxman, B., Marrs, C.F., Eisenberg, J.N., 2015a. Effects of selection pressure and genetic association on the relationship between antibiotic resistance and virulence in Escherichia coli. Antimicrob. Agents Chemother. 59 (11), 6733-6740.

133. Zhang, Q.-Q., Ying, G.-G., Pan, C.-G., Liu, Y.-S., Zhao, J.-L., $2015 b$. Comprehensive evaluation of antibiotics emission and fate in the river basins of China: source analysis, multimedia modeling, and linkage to bacterial resistance. Environ. Sci. Technol. 49 (11), 6772-6782.

134. Zhang, T., 2016. Antibiotics and resistance genes in wastewater treatment plants. AMR Control, 9.

135. Zhang, W., Huang, M.-h., Qi, F.-f., Sun, P.-z., Van Ginkel, S.W., 2013a. Effect of trace tetracycline concentrations on the structure of a microbial community and the development of tetracycline resistance genes in sequencing batch reactors. Bioresour. Technol. 150, 9-14.

136. Zhang, Y., Zhang, C., Parker, D.B., Snow, D.D., Zhou, Z., Li, X., 2013 b. Occurrence of antimicrobials and antimicrobial resistance genes in beef cattle storage ponds and swine treatment lagoons. Sci. Total Environ. 463, 631-638. 
137. Zhu, Y.-G., Johnson, T.A., Su, J.-Q., Qiao, M., Guo, G.-X., Stedtfeld, R.D., Hashsham, S.A., Tiedje, J.M., 2013. Diverse and abundant antibiotic resistance genes in Chinese swine farms. Proc. Natl. Acad. Sci. 110 (9), 3435-3440. 


\section{Figure Captions}

Fig. 1 Mean relative abundances of ARGs in swine wastewater

Fig. 2 Mechanisms of horizontal gene transfer among bacteria

\section{Table Captions}

Table 1 Intrinsic resistance mechanisms and hosts of ARGs and their shift in anaerobic treatment processes 


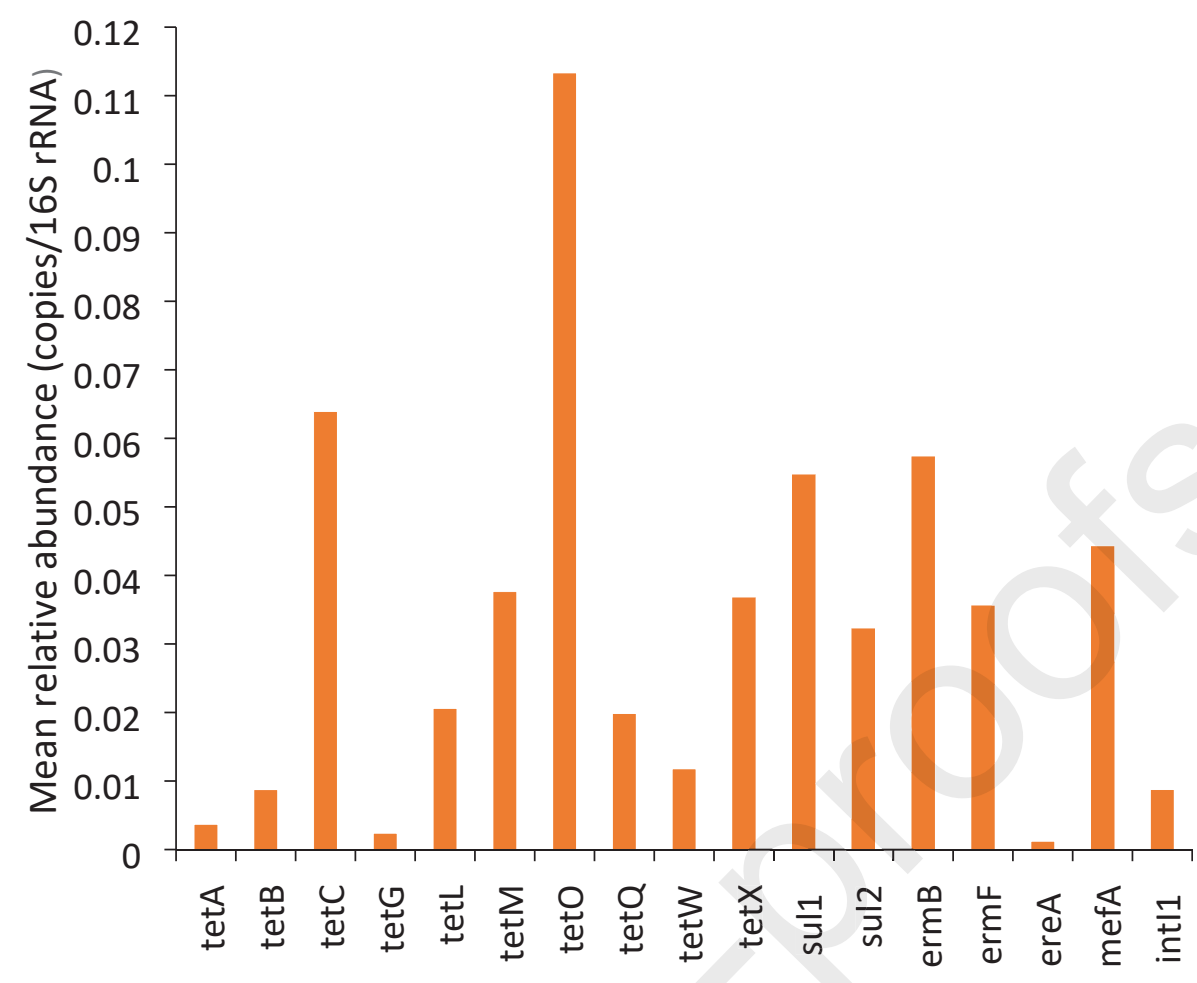

Fig. 1 Mean relative abundances of ARGs in swine wastewater 
1. Bacterial transformation

Release of

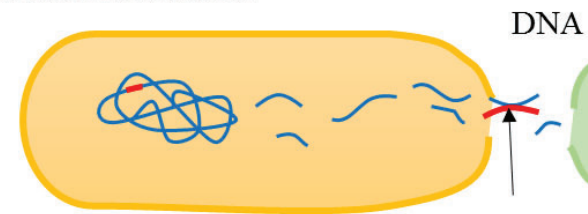

Donor cell

ARGs

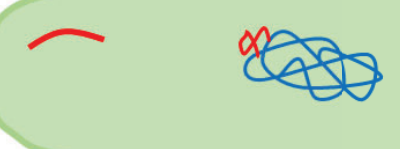

Recipient cell

2. Bacterial transduction

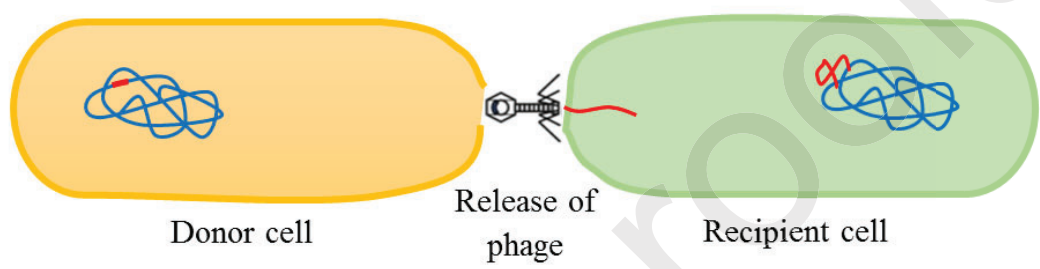

3. Bacterial conjugation

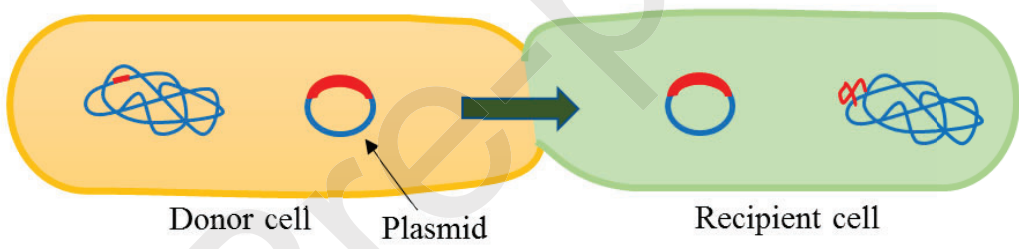

Fig. 2 Mechanisms of horizontal gene transfer among bacteria (modified from Furuya and Lowy (2006)) 


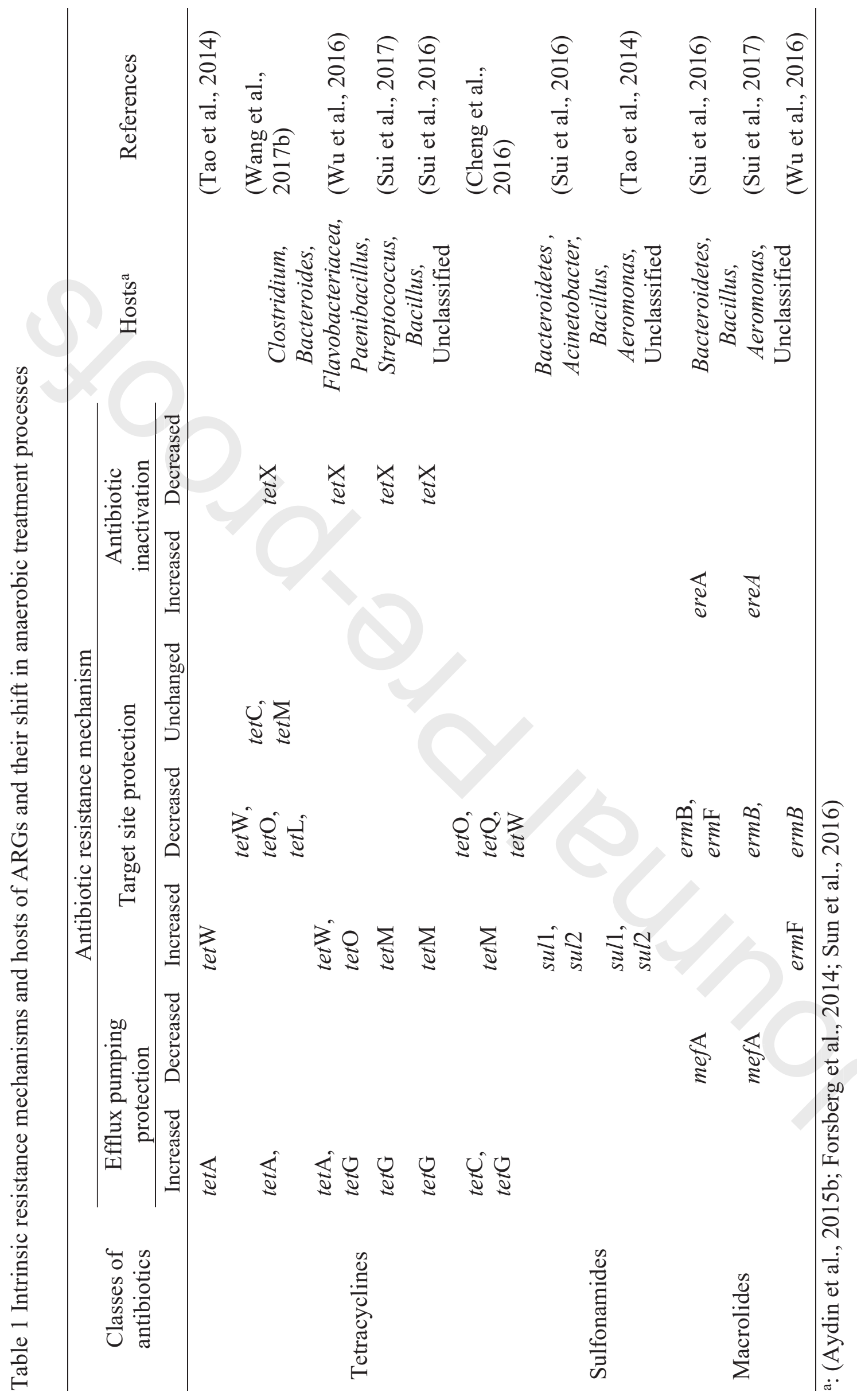

